\title{
PERCEPTIONS OF RESEARCH IN EDUCATION FOR SUSTAINABLE DEVELOPMENT: AN INTERNATIONAL PERSPECTIVE
}

\author{
Anita Pipere \\ Daugavpils University, Latvia \\ Jyrki Reunamo \\ University of Helsinki, Finland \\ Marion Jones
}

Liverpool John Moores University, Great Britain

\begin{abstract}
This paper reports on a study undertaken to investigate international perspectives of what constitutes research in education for sustainable development (ESD). By employing inductive thematic content analysis, the authors sought to examine the perceptions of 66 ESD researchers from 19 countries. The findings reveal a concern with the methodological aspects of research and an emergent need for synergy between the methodology of educational research and specific themes relevant to ESD research. The significant overlap of themes and aspects of ESD research apparent across the different contexts within which the researchers were embedded indicates a unified core of ESD research, although there is also evidence of contextual factors influencing the research agenda. Based on the findings of this study, the paper concludes that there is an overlap between educational research and ESD research, but that the latter has its own specific aims, themes and political supporters. In an endeavour to develop a shared understanding about ESD research across disciplines and research context, a common language has to be developed to facilitate a constructive dialogue and research capacity building in this novel field.
\end{abstract}

Key words: ESD research, educational research, researchers, methodology

\section{Research in education for sustainable development: Looking for the right questions to ask}

Reaching a consensus and improving awareness about research related to issues of global concern requires constant monitoring of state of the art advances that are highly specific and thus poses a significant challenge. Given the apparent dearth of studies on education for sustainable development (ESD), this paper seeks to draw attention to this relatively novel and underdeveloped field by probing the various research approaches used by educational researchers, including the beliefs, presuppositions and values underpinning their practice.

Recently, ESD has emerged as a critical area of academic research globally both with regard to the urgency of the substantive issues that need to be addressed in response to an 
international sustainability agenda and a lack of clarity regarding the way in which the field is conceptualized as a research domain. Bibliometric data shows a steady increase in the number of ESD articles published between 1990 and 2004 from 64 to 162, while the number of academic journals accepting ESD papers for publication increased from 27 in 1990 to 78 in 2004. This positive trend was accompanied by a growing number of authors publishing in this field (Wright \& Pullen, 2007). For example, using the same search criteria, 1,479 ESD journal articles were identified for the period from 1990 and 2005, compared with the 1,338 articles published in the much shorter time span between 2005 and 2010. Thus, the bibliometric evidence suggests an almost threefold increase. And yet, ESD research is still in its inception and there is an urgent need for research capacity building, which can be achieved by focusing researchers' attention to this relatively novel field (McKeown, 2007).

The perceptions of the researchers about the nature and purpose of ESD research will be examined, whilst recognizing that these perceptions have gradually evolved through a process of social and collaborative learning (Daniels \& Walker, 2001; Keen, Brown, \& Dyball, 2005). Participation in conferences, collaborative projects, local and global networking, while teaching at their respective universities has allowed the researchers to construct and re-construct the research paradigms in which they locate their ESD research.

This study is to be understood as a scoping exercise which accords ESD the status of a legitimate topic for educational research and reflects the current state of development of the field. According to Labaree (2003), educational researchers are used to respond to society's demands in terms of providing explanations for educational problems at a given time. However, the expectation to provide answers to educational problems presents researchers with huge challenges and requires new and creative approaches. The need to clarify epistemological and methodological concepts and to agree a shared definition of tools is recognized by many in the field. Urgent answers were, therefore, sought in relation to the following questions: What exactly is to count as ESD and what does not? What are the aims and boundaries of ESD research? What are its essential characteristics? (McKeown, 2007)

This paper begins by identifying the themes of ESD research and will then go on to explore possible synergies across them with regard to the problems and advances encountered in educational research (entire field) and specifically in the field of ESD. Then, the different aspects of research in ESD in an international context will be considered and any issues arising will be discussed. Therefore, in recognition of the urgency of research capacity building in ESD and in pursuit of developing a shared vision for ESD research this study seeks to find out answers to the following questions: 1) What is ESD researchers' ideal conceptualisation of ESD research? 2) What commonalities, if any, do ESD researchers perceive between contemporary educational research and ESD research? 3) What are the distinctive traits of ESD research as identified by ESD researchers?

The data generated in response to these questions will be used to determine the level of resonance that exists between the perceptions of ESD researcher participating in this study and research perspectives located in other contexts. 


\section{Methods}

\section{Participants}

Since researchers in ESD could be viewed as a specific hard-to-reach population, it was not intended to conduct the research with a representative sample. A purposive opportunity sampling strategy was used deliberately targeting those who are thought to have information that will help to achieve the study's aims. In an attempt to minimize the potential of bias, the participants were recruited from a diverse range of geographical, national and academic backgrounds whilst sharing the basic criterion of disseminating their research on ESD in academic peer reviewed journals and international conferences. Initially, the participants were recruited using the authors' previous and current professional contacts within the academic community, mainly within a European context. In the introductory letter, the participants were asked to circulate the invitation to participate among their colleagues who they believed to be active ESD researchers. Thus, a snowball sampling strategy was employed. It introduced a certain degree of distance between the researchers and the potential participants and thereby avoided the recruitment of "agreeable respondents" who might have voluntarily or unintentionally empathized with members of the researchers if approached directly.

The participants $(\mathrm{N}=66)$ represented researchers from 19 countries, including five Eastern-European countries (30), seven Western European countries (19), three Scandinavian countries (11) and other non-European countries (Australia, Taiwan, USA) (6). The majority of the participants were between 36 and 69 years of age with research experience ranging from 4-24 years in general and 3-11 years for ESD specifically. For some, the first contact with ESD research was facilitated mainly at conferences and seminars (17) and through teaching at university (11). For others, it was projects (7) and masters or doctoral studies (7) that provided the means of introduction to this field. Nongovernmental organizations and other institutions provided researchers with access routes to ESD, but to a lesser degree. Only three researchers reported discovering ESD through reading the literature and relevant documents. Ten researchers provided the following responses: can't remember; childhood experience; parental role models.

The main socio-demographic characteristics of the participants are reflected in Table 1.

Table 1. Selected socio-demographic characteristics of the ESD researchers sample

\begin{tabular}{lcr}
\hline Background characteristics & N & Percentage \\
\hline Gender: & & \\
\hline Male & 22 & 33.3 \\
\hline Female & 44 & 66.7 \\
\hline Status: & & \\
\hline Under-graduate student & 2 & 3.03 \\
\hline
\end{tabular}




\begin{tabular}{lcc}
\hline Post-graduate student & 12 & 18.2 \\
\hline Holder of a doctorate & 32 & 48.5 \\
\hline Professor & 20 & 30.3 \\
\hline Doing research*: & & \\
\hline As full-time researcher & 12 & 18.2 \\
\hline As part of contractual employment & 43 & 65.2 \\
\hline As a student & 9 & 13.6 \\
\hline As a hobby & 2 & 3.03 \\
\hline Academic background*: & & \\
\hline Natural sciences & 18 & 27.3 \\
\hline Educational sciences & 39 & 59.1 \\
\hline Humanistic sciences & 6 & 9.10 \\
\hline Social sciences & 9 & 13.6 \\
\hline Preferred research methods: & & \\
\hline Quantitative & 15 & 22.7 \\
\hline Qualitative & 37 & 56.1 \\
\hline Mixed & 14 & 21.2 \\
\hline
\end{tabular}

Sequel to Table 1 .

*Some researchers had academic background in two fields of science

*Some post-graduate students were working as full-time researchers or doing research as part of contractual employment

The sample presented in Table 1 reflects a high degree of diversity in terms of the participants' gender (although the majority being female), qualifications (holding a doctorate or not), working pattern (full or part-time), academic background (majority from educational and natural sciences) and preferred research methods (quantitative, qualitative or mixed). The diversity of the sample was seen as helpful in capturing a wide range of perspectives and voices and, by doing so, enhancing the balance and credibility of findings.

\section{Data collection and analysis}

Data collection was conducted primarily via contacting the participants by e-mail and resulted in a response rate of about $80 \%$. In addition further responses were received from delegates attending the international ESD conference in Turkey (Anadolu University, 2008), where an invitation to fill in the questionnaire had been included in the conference pack. The participation was voluntary, confidential and based on informed consent. It also included feedback of results on conclusion of the study. Initial demographic questions were followed by open-ended questions: What about ESD research in general? In your personal opinion, what should ESD research be like? Provide a description of your ideas.

Qualitative text data in the form of open-ended survey responses is often elicited to explore different dimensions of respondents' experiences, and this type of data can provide a somewhat rich description of respondent reality. The literature provides further arguments in support of this approach. Erickson \& Kaplan (2000) maintain that in comparison to interviews or focus groups, open-ended survey questions can offer greater anonymity to respondents and often elicit more honest responses. They can also capture diversity in responses and provide alternative explanations for those that closed-ended survey questions 
fail to capture (Miles \& Huberman, 1994; Pothas, Andries, \& DeWet, 2001; Tashakkori \& Teddlie, 1998).

The data was analysed using an inductive approach to thematic content analysis with the aim of identifying prominent and consistent themes across participants (Baxter, 1991). The advantage of this approach lies in its capacity to allow categories to emerge from the data, rather than imposing them through theory- or research-driven hypotheses and assumptions (Creswell, 1998; Patton, 2002). Inductive themes, drawn from the data, are often useful in new areas of research, although Joffe and Yardley (2003) include the caveat that no theme can be entirely inductive or data driven, since the researcher's knowledge and preconceptions will inevitably influence the identification of themes.

Adopting a mixed methods approach (Bond, Holmes, Byrne, Babchuck, \& KirtonRobbins, 2008; Jithoo, 2010; Hutchins, Hastie, Starkey, Hilton, \& Clark, 2005, etc.) in the analysis of qualitative data constituted a hybrid technique, which according to Bauer and Gaskell (2000) is highly flexible and can be adapted to the research questions, the participants, the method of data collection and characteristics of data. Weber (1990) believes that the best content analytic studies use both qualitative and quantitative operations on texts.

In conducting a thematic content analysis (Malterud, 1993), the following procedure was used. Firstly, all the material was read to obtain an overall impression and for the researchers to become aware of any preconceptions. Secondly, the units of meaning with a primary focus on the expression of an idea (i.e. case) (Minichiello, Aroni, Timewell, \& Alexander, 1990), not individual items of language (for instance, single words, phrases, sentences, paragraphs), were identified and coded. These units of meaning were then distilled into broader themes.

The number of cases captured within each theme provided the researchers with an indication of the extent to which this mapping exercise revealed a shared understanding about the themes amongst ESD researchers. Due to the constraints imposed on the basis of the size and composition of the sample, it is not possible to present any statistically significant findings that can claim to be of generalisable value. Instead, this study seeks to highlight ESD researchers' perceptions of their field with a view to using some of these findings as a basis for follow-up large-scale study.

\section{Findings}

\section{Profiling ESD research aspects: Towards a holistic picture of educational research}

At first, the answers to the first research question will be examined What is ESD researchers' ideal conceptualisation of ESD research? An overview of the themes that emerged from the content analysis of data (answers to the open-ended question) will be provided. The length of the answers provided by the respondents varied from 5 to 394 words. On average, the length of the answers was 98 words. In total, 158 semantic units were generated leading to the emergence of six themes with one theme (research 
methodology), generating an additional five sub-themes. The number of cases for each theme and relevant percentage are shown in Table 2 . The majority (67\%) of the respondents stated one idea (case), a third (32\%) cited two and only one participant combined three.

The most frequently populated theme was 'Research methodology' (53\%), which was further sub-divided into 'Philosophical background'; 'Disciplinary and theoretical background'; 'Qualitative and quantitative research'; 'Theoretical versus applied research' and 'Type of research' (Table 2). Out of the five sub-themes, 'Qualitative versus quantitative research'(18\%) and 'Disciplinary and theoretical background' $(16 \%)$ were the most prominent, followed by 'Aim of ESD research' (14\%), 'Research environment' (11\%), 'Problems with the research for ESD' (10\%) and 'Themes of research for ESD' $(9 \%)$. In an attempt to answer the second research question (What commonalities, if any, do ESD researchers perceive between contemporary educational research and ESD research?), the researchers will focus on these themes. The original voices of the participants are provided in the form of citations presented in italics. To enhance coherence and clarity of argument, the presentation of data will be followed by discussion.

\section{Philosophical background: Developing a common language and a shared understanding}

Nine researchers mentioned the need for a philosophical perspective that can inform ESD research. Four researchers stressed the need for a value-based approach, while three cited a systemic approach and two appealed to the purposefulness and comprehensiveness (verbatim quotes in italic) of obtained knowledge. Speaking about the subject of ESD research itself, the respondents suggested that it should be about the dualism [between personal freedom and collective direction toward sustainability] and how it is addressed in different cultural contexts, and how it will be possible to bridge this and simultaneously ensure the preservation of the special character of the culture. This is comparable with the tension between feeling optimally free and acting in a certain direction [towards sustainability].

This stance resonates with Dewey (2009), who advocates the view that educational practice needs to have a serious philosophical foundation. In a similar vein, educational research is to be underpinned and informed by a critical discourse on research methodology and thereby help frame and analyze philosophical problems specific to education (Moses, 2002) - both applications are relevant to ESD research, though they are scarcely considered by publications in the area of ESD research (Mandolini, 2007). Although debates about the environment, poverty and future generations are philosophically vigorous, such issues are generally regarded as being of marginal significance by the wider body of Anglo-American philosophers (Palmer, 2004, as cited in Everett, 2008).

Pointing to a value-based research approach, Howe (2008) suggests that educational research should be rooted in and guided by the values associated with a genuine form of democratic politics. According to Moses (2002) the "philosophers of education may also alert educators to the value and right headedness of some movements, and thus to the need for changes in policy and practice" (p. 14). Even if "we are entrenched in a particular way 
of thinking about the world, one in which we have been trained, one that seems to suit our ends and our dispositions" (St. Pierre, 2006, p. 257), we need not only be willing to hear others, but also develop a common language to understand each other and thereby facilitate a constructive and critical dialogue across a diversity of perspectives and constituencies.

\section{Developing an inter-disciplinary approach}

The value-laden aspect of research methodology was broadly addressed in the responses given by ESD researchers ( 25 cases). In ten cases, inter-disciplinarity in ESD research was prioritized, emphasizing the widest scope of involved dimensions: The sense of interdisciplinarity is based not only on natural and historic variables, but also on normative dimensions (this means that they involve values, morality, cultural views on nature and human essence). Nevertheless, some scholars stressed the sole importance of their own discipline, such as social sciences, education or natural sciences, ecology. The majority of the researchers, however, perceived the field of ESD research as based on different approaches and theoretical perspectives and were aware of theoretically eclectic interpretations of the field. There was evidence of a more radical contextual view: ESD research should not be based on purely theoretical models: an interpretation of ESD statements and criteria depends very much on specific social circumstances which, in turn, are related to economy and ecology. This coincides with the opinion of Berliner (2002, p. 19) who maintains that "in education, broad theories and ecological generalizations often fail because they cannot incorporate the enormous number or determine the power of the contexts within which human beings find themselves" (p. 19).

The views of the researchers participating in this study resonate with the idea that simple interdisciplinarity as bounded by certain sciences is not enough. More effective theoretical pluralism reaching beyond the guiding assumptions and methods of the physical, behavioural and social sciences are necessary; alternative traditions and modes of inquiry are called for to complement the traditional, convenient habits of mind (Bullough, 2006). This stance should resonate with educational researchers, who continually tend to rebuild and extend the foundations of the field leading to dispersion of resources into a variety of parallel projects that are scattered across the terrain, each working its own discrete portion of the educational context and building its own intellectual foundations for analysing that context (Labaree, 2003).

\section{The paradigm wars - mixed methods}

The researchers participating in this study paid particular attention to the paradigm wars and the majority agreed that ESD research asks for both qualitative and quantitative methods, depending on the research question. However, in nine cases a marked inclination towards the qualitative paradigm was evident (mostly qualitative, situational and contextual, different kinds of people's voices), which can be explained largely by the background of the researchers. Five researchers mentioned that this should be high quality 
and valid research that follows strict scientific criteria: it is not the question of whether ESD research is qualitative, quantitative or mixed, basic or applied, theoretical, philosophical or naturalistic. What matters is the research question, the perspective of sustainability, and trustworthiness of research itself. Only one researcher mentioned that ESD research, in general, should be quantitative and statistical. The issue of the methodological dichotomy is linked to the multi-disciplinarity of ESD research and, as it is indicated by one of the research participants, every discipline should follow its own methodology though looking at a common aim.

As to the specific type of research, action research and holistic education research were mentioned as consistent with the qualitative point of view and a recognition that action research has, for a long time, warranted its potential as a tool for diminishing the hindrances to the solutions of complex issues in society (Salîte, 2008). Also, longitudinal and comparative studies were mentioned as an appropriate research design for ESD.

Many educational researchers (Paul \& Marfo, 2001; Feuer, Towne, \& Shavelson, 2002; Labaree, 2003, etc.) imply that "quantitative and qualitative research methods should not (and cannot) be distinguished and set in opposition to one another on the grounds that quantitative methods are inherently and exclusively positivistic and suited only for confirmation, whereas qualitative methods are inherently and exclusively interpretative and suited only for understanding" (Moses, 2002, p.2). Together, they can often support stronger scientific inferences than when either is employed in isolation (Feuer, Towne, \& Shavelson, 2002). Undoubtedly, the idea that educational researchers need to develop and apply a high degree of methodological sophistication and flexibility to ESD research can be attributed.

\section{The theory - research-practice nexus}

Ten researchers referred to the relationships between theory, research and professional practice. Both the combination of theoretical and applied aspects of ESD and practical implementation of results at the post-research stage were mentioned. The researchers suggest going beyond the statement of facts and trends and moving towards the suggestions of means, approaches and methods which may improve the current situation. The integrative aspect of educational research is illustrated by the six models of ResearchPractice in Education presented by Burkhardt and Schoenfeld (2003):

- teachers read about research and implement it in their classrooms;

- summary guides (professional organisations regularly produce research distillations);

- general professional development;

- the policy route;

- the long route of the productive relationship between educational research and practice;

- experimental design. 
Currently, there is evidence of the second and fourth model being the most prominent in ESD research. Summary guides like the UNESCO guidelines published during the Decade of Education for Sustainable Development (DESD), intended for educational professionals and the public, reflect policy elaborated by UNESCO. The development or implementation of other models will require long-term initiatives and a larger number of ESD researchers. Furthermore, ESD research needs to embrace the research traditions of humanities, science, and engineering and use them in a complementary way. For instance, as in engineering, ESD research should also, but not exclusively, be concerned with the designing and systematic development of high-quality solutions to practical problems (Burkhardt \& Schoenfeld, 2003).

\section{The ESD research environment}

The researchers participating in this study indicated that ESD research should be conducted collaboratively, by allowing research participants (students, education legislators, mentors, teachers and teacher educators) to act as co-researchers and by creating teams and networks to conduct collaborative inquiry: the focus is on encouraging a democratic process in which the participants are co-researchers who participate in designing research that will collect data about the experience they will undergo as co-subjects of the research. Relating to the call for action research mentioned, the participants held that such research should be carried out with people, not on them.

Also, the literature on educational research stresses the importance of collegiality and collaboration and the development of more democratic, multi-professional, interdisciplinary, and cross-gender social relationships (Lagemann, 1997). It also highlights its reliance on relationships between researchers and those engaged in professional practice as critical, for instance, teachers, administrators, curriculum developers, university deans, school board members and a host of others (Feuer, Towne, \& Shavelson, 2002).

The challenge for the field of education and for ESD research in particular is to bring diverse communities - both scientific and otherwise - together to integrate theories and empirical findings across domains, cultures and methods (Labaree, 2003), since ESD as a value-based area cannot work fragmentally or separately in just a few spheres or processes of organisation. To be successful, it has to pervade the various research paradigms and be interwoven at the micro-, meso- and macro- level of the system under consideration.

\section{Distinctiveness of ESD research}

Answering the third research question (What distinctive traits of research attributed to the particular field of ESD research are recognized by ESD researchers?), this section will focus on 1) aims and themes; 2) exemplary cases; 3) issues arising from ESD research. 


\section{The aims and themes of ESD research}

The aims of ESD research were one of the three themes that elicited the second highest frequency of responses (22 cases). The majority agreed that ESD research should be aimed at 1) examining the current situation; 2) developing models for personal and a societal future life; 3) changing human awareness and actions towards more sustainable lifestyles and responsibility towards the rest of the world. Five researchers prioritized a new vision of education (awareness, self-regulation, world views, etc.). Just a small minority of the participants mentioned the evaluation of ESD and the need to develop contextualized educational models.

If education is defined as the deliberate activity of helping learners to develop a deeper understanding and skills, then the instructional dynamics occurring in schools or elsewhere becomes the unique province of education research. It is possible to agree with Ball and Forzani (2007) that the core of the educational process should be knowing about and understanding the dynamic relationships among teachers, learners, content, environments. However, if education is re-defined to include global existential and value-laden aspects, as it is the case with ESD, a researcher needs a visionary mind set while focusing on the questions of ends, of the good, as they invite others to engage in the struggle with what ought to be done, even as outcomes are inevitably uncertain, almost happily so (Bullough, 2006). Furthermore, the topics of ESD research emerging from this study show that the majority of participants recognize a visionary perspective of ESD research towards changing human lifestyles, which is clearly identified in 14 cases (9\%). The largest number of cases pertains to innovations in education (schools, universities, teacher training) focusing on sustainable development. Other topics reflect a diverse range of issues: 1) existential and societal (human life and its sustainability/unsustainability, characteristics of the citizens of a sustainable society); 2) epistemological and cultural (basic knowledge of sustainability, indigenous knowledge); 3) instrumental (motivation and tools for reaching sustainability). The majority of the researchers accentuated that ESD research should focus on the discovery of individuals' intellectual, moral, social, affective and behavioural dispositions towards their present/future life and evaluation of sustainability/ unsustainability of this life, 1) testing instruments for measuring the current dispositions and 2) creating the tools and verifying their efficiency for changing the unsustainable dispositions.

\section{Exemplary cases of ESD research}

Research that is valued by external evaluators and has a high impact factor on users tends to be the kind of research that researchers readily use in their own self-presentation. In this study, the exemplary cases were also used by participants to define effective ESD research. Therefore, these cases can also complement the previously discussed themes of ESD research. They represent studies ranging from recognisably large-scale institutional projects to small-scale, applied studies. One such example, mentioned by the participant from Australia, is the Australian Research Institute for Education for Sustainability (ARIES) 
which conducted research for educational systems change at a regional and national level (Denby, Tilbury, \& Cerone, 2007; Henderson \& Tilbury, 2004; Tilbury \& Ross, 2005). Other similarly laudable initiatives noted in the answers from UK participants are the training projects on the Welsh dimension of ESD and Global Citizenship (e.g., DCELLS, 2008; DELLS, 2006) and an action research project (a cooperative inquiry) which is seeking to enable a team of teacher educators to develop the Cert Ed/PGCE (Lifelong Learning Sector) to integrate ESD into the curriculum (Cook, Cutting, \& Summers, 2010; Summers, 2010). The small-scale applied projects are concerned with the use of multi-level learning with local teachers to broaden their awareness of "being", to the study of selfdeception/denial and greed as factors that prevent individuals (adult and teens) from transitioning to a sustainable lifestyle.

Two cases related to theoretical elaborations, namely the creation of the pedagogical systems theory focused on early childhood education (Härkönen, 2003) and models of implementing ESD strategic principles at various levels of education. It is interesting to note that the balance between the applied and theoretical nature of named projects matches the idea of a methodological equilibrium apparent in ESD research.

\section{Issues emerging with regard to research in ESD}

Drawing on the relatively extensive research experience of the participants allowed the researchers to identify a range of issues with regard to the development and sustainability of ESD research. The responses generated by the 66 researchers are highly diverse and suggest that the assumption that ESD research is a well-developed field of educational research needs to be treated with caution. However, they provide evidence to suggest that there is a strong link between the findings of this study highlighted earlier and issues identified by the participants:

- unclear, irrelevant or taken for granted theoretical considerations with rather limited practical value;

- lack of broadly discussed and generally accepted methodology, methods, tools;

- the illusion that we can completely rely upon the information from the past (quantitative research) to make suggestions for future;

- difficulties with programme implementation on different levels;

- fragmented studies;

- lack of incentives for researchers and research participants.

In two cases, the researchers referred to the substantive areas in which ESD research tends to take place, implying that it is hard to identify generic criteria/content of sustainability or that ESD has been reified to such an extent that we no longer ask what it means, and almost never consider its relationship to sustainable development itself. For instance, one researcher highlighted the insufficient reflection given to ESD research in educational media. 


\section{Considering the ESD research agenda in relation to different contexts}

In order to elicit various discourses about the ESD research agenda in different contexts, it would be helpful to observe the outcomes of discussions held by international experts during consultations, workshops and presented in academic writing. Further analysis will be based on three items: 1) the research agenda in higher education for sustainability (HES) articulated during the Halifax Consultation in 2005 (Wright, 2007); 2) the strategic research agenda for the UNDESD presented during a joint UNU-UNESCO workshop in Paris 2006 (McKeown, 2007); 3) research trends in the United States identified in an article by Heimlich (2007).

\section{The Halifax consultation - the research agenda for higher education for sustainability (HES)}

The Delphi Technique, a systematic, interactive forecasting method, which relies on a panel of experts, was used at this workshop incorporating three rounds of questionnaires: 1) the wording of written answers to open-ended questions about the priorities of HES research for the future as discrete questionnaire items complemented by new items from discussions; 2) the review of items on a Likert-Scale of 1-5 in terms of perceived importance for future HES research and inter-group agreement on 19 highly important themes; 3) the selection of the 10 most important research areas from 19 themes and development of a list based on participant rankings (Wright, 2007).

The methodology of the Halifax workshop partly coincides with the research methodology employed in this study in that the initial open question avoids predetermining or eliciting specific participant responses. The diversity of answers provided indicated the scope of the research (orientation towards ESD in general or towards HES) and was also reflected in the different backgrounds of the participants.

Although there is no striking disparity in the general framework of categories developed in this study (Table 2) and in the Halifax consultation (Wright, 2007), there are some notable distinctions: 1) the Impacts of Teaching and Learning Methods received the top ranking in Halifax, whereas, in this study, they were mentioned only indirectly; 2) the list of the Halifax categories contains a mix of categories related to different domains. The largest proportion is related to content issues (for instance, individual and social change, transformative learning, etc.). Only a few items refer to research methodology (e.g., the philosophy and epistemology of HES, case study analysis) or to research policy (legitimising HES research and practice). Probably the narrower focus of HES implicitly suggests a preference for turning to the content areas of research.

As for the similarities, from the seventeen categories ranked by the participants of the Halifax consultation, twelve were in tune with those obtained in this study. They are (starting from the highest rank): 1) The Impacts of Teaching and Learning Methods; 2) Mainstreaming Sustainability; 3) Institutional Culture and Organisational/Governance Structures; 4) Evaluating Educational Approaches; 5) Legitimising HES Research and Practice; 6) Transformative Learning; 7) Philosophy and Epistemology in HES; 8) 
Disciplinarity, Transdisciplinarity and Interdisciplinarity; 9) Capacity-building; 10) Individual and Social Change; 11) Inclusiveness and Voice in Sustainable Development; 12) Networking.

Two categories with direct relevance to HES were not a priority in this study. While omitting the categories of Case Study Analysis and Leadership and Management, the participants mentioned action research and longitudinal studies. Furthermore, the number of exemplary cases among the categories of this study shows that the research participants are already thinking about their research in terms of 'best practice' cases.

Table 2. The themes related to ESD research elicited from the textual data of ESD researchers

\begin{tabular}{lcrr}
\hline Theme & Number of cases & Percent \\
\hline Aim of ESD research & 22 & 14 \\
\hline Research methodology & 83 (in total) & 53 \\
\hline$\bullet$ & Philosophical background & 9 & 6 \\
\hline$\bullet$ & Disciplinary and theoretical background & 25 & 16 \\
\hline$\bullet \quad$ Qualitative vs. quantitative research & 28 & 18 \\
\hline$\bullet \quad$ Theoretical vs. applied research & 10 & 6 \\
\hline$\bullet \quad$ Type of research & 11 & 7 \\
\hline Research environment & 17 & 11 \\
\hline Themes of research for ESD & 14 & 9 \\
\hline Problems with the research for ESD & 15 & 10 \\
\hline Exemplary cases of ESD research & 7 & 4 \\
\hline
\end{tabular}

It appears that the research agendas in both studies overlap, though the specific characteristics of research methodology and research focus led HES experts to emphasize the content areas specific for HES, while the ESD researchers in our study stressed the methodological aspects of ESD research. On a global scale, promising signs of a consensus are emerging from the European and North American international academic community of ESD researchers regarding the important issues of the research agenda: research aims, philosophical and disciplinary background, themes of research and collaborative way of doing research.

\section{UNU-UNESCO workshop - strategic research agenda for UNDESD}

The workshop organized in 2006 in Paris was based around a series of small group discussions of seven themes prepared by the UNESCO and the United Nations University (UNU). Each discussion session used a predetermined set of questions, themes, key words to prompt discussions.

The relative congruence between the workshop and this study is apparent and useful in discovering the essence of ESD research in general, as well as in relation to the diverse backgrounds of the participants. However, the methodology of the UNU-UNESCO workshop was different from the one used in the Halifax consultation and in this study, for 
it was based on predetermined themes of discussions and limited to 28 invited participants from 20 countries around the world.

The core of the strategic research agenda created in this workshop provisionally aligns with the UNESCO political agenda and the focus on instrumental, functional and structural aspects of ESD research. The comparison of the major themes emerging from the discussion in Paris (Mckeown, 2007) with those generated by this study reveals that perhaps all major themes, except for the Analysis of Policy, are in one way or another touched upon. The Clarification of the Concepts demanded by workshop participants in our study was implicitly interwoven with methodological categories and in the discussion of ESD related issues. Rising of Awareness, Analysis of Curriculum related to sustainable development, Evaluation of Practices to Identify Good Practices and the Eventual Development of Case Studies were issues repeatedly mentioned in the workshop, and these items were close to the aims and exemplary cases of ESD research. Methods for Building Capacity for ESD Research highlighted in the workshop were of relevance to the different methodological issues (disciplinary background, researchers, and problems with ESD research) identified in this study. The theme Learning was observed in twelve responses of ESD researchers representing different research environment (for instance, action learning models, teachers' learning, lifelong learning, distance learning, learning society, transdisciplinary learning, learning environments, etc.). However, due to the high degree of diversity apparent in the underlying contexts of learning, it was not discerned as a separate theme.

On the basis of these synergies, the research agendas created by the participants in both studies are related. Nevertheless, the different methodologies, the context of participants and workshop organisation determined the more politically and normatively oriented agenda and terminology of the UNESCO workshop, whereas the ESD researchers participating in this study avoided reference to political matters placing less emphasis on the cultural dimension. Instead, the focus was predominantly on the methodological aspects of ESD research.

\section{ESD research trends in the United States}

The analysis is based on the recent article by Heimlich (2007) Research trends in the United States: EE to ESD, where the author has attempted to classify the major trends of environmental education (EE) and ESD research in the US. According to Heimlich (2007) "in an ideal world, a unified research agenda would exist upon which research and evaluation studies could be built and intertwined" (p. 220). This view both substantiates his study and shows the relevance of his theoretical analysis to the current paper.

The methodology used by Heimlich (2007) relates to the area of descriptive analysis. In contrast to the studies described beforehand, the data had not been obtained from the research participants. Also, the elicited themes reflect the research trends in only one country, although, in its scope, Heimlich's (2007) study is similar to those previously analysed ESD research agendas that deal with ESD research in general. 
Heimlich (2007) concedes that the themes he discerns are not comprehensive and that they illustrate how programmes lead towards outcomes desired by dominant stakeholders (government, schools, communities, agencies and NGOs) through studying what these programmes are, how they are constructed, how they work, in what ways they affect the learner, society, and lead to change for sustainability. Heimlich (2007) distinguishes between formal, non-formal and informal education. Formal education represents several broad and disparate areas: Action Research, Cultural Relevance, Experiential Education, Place-based Education and Campus Greening. Comparing it with this study, two trends are of striking similarity: action research and cultural relevance, unlike the terms 'experiential education', 'place-based education' or 'campus greening', which were not encountered in the answers of European researchers at all. However, the idea about direct experience through the learning environment was mentioned explicitly. In his (Heimlich, 2007) discussion of non-formal and informal education, four categories are discerned: Freechoice Learning, Adult Environmental Learning, Citizen Science and Community-based Education. This is in contrast to our study which perceives adult environmental learning and citizen science as aspects of lifelong learning and citizen education.

As Heimlich (2007) concludes "there is no paradigm dominating research in ESD and EE in the United States today" (p. 224), and it was difficult to identify similarities between Heimlich's (2007) and previously analysed studies, due to differences in terminology and point of view. However, it became apparent that there was a huge impact of the context and differences in research development in different regions of the world, which prompts the elaboration of specific regional ESD research agendas.

\section{Conclusion and recommendations}

The process and the results of this study allow the professional community of ESD researchers to engage in both professional criticism and self-correction (Popper, 1959, as cited in Feuer, Towne, \& Shavelson, 2002), regarding the further development of ESD research. The general picture that emerges reflects a great diversity in the way in which ESD research is perceived. It not only provides us with responses to why, what, who and how questions, but also refers to both issues and best practice with a strong emphasis on the methodological aspects and the recognized issues.

The overall consensus emerging from the data was that research on ESD poses problems, challenges and advances that are well-described in the research literature about educational research in general. It is evident that ESD research mainly follows the struggles and advances in educational research, while having its own specific aims, themes, and political supporters. There is, therefore, a need for a synergy between the methodology employed in educational research and the specific themes relevant to ESD research.

The research findings suggest that the ESD researchers hold the view that ESD research starts with the examination of the current situation to develop personal/societal future life models prescribing the change of human awareness and actions towards developing more sustainable lifestyles and adopting responsibility for the world. These 
changes can be introduced by innovations in education (schools, universities, teacher training, etc.) focusing on sustainable development.

The review of the four studies on the ESD research agenda demonstrates that answers to research questions are heavily influenced by the research context and methodology employed. And yet, this study shows that a general framework of ESD research is emerging from the overlapping of suggested themes and aspects of research. Each of the four studies has its strengths and weaknesses to be considered in order to develop a sustainable idea about the what, why, where and how of ESD research.

Finally, it is necessary to acknowledge the limitations of this study. By using a purposive/snowball technique, it is not possible to guarantee that the participants' responses were not influenced by their relationship with the researchers and the conference convenors. It should also be acknowledged that a thematic analysis of qualitative data abstracts issues emerging from the lived social realities of those participating in the research and is thus influenced by the researcher's sense of how it connects, rather than the inter-relationship of themes in the participant's mind or lifeworld (Boyatzis, 1998). However, Joffe and Yardley (2003) argue that the goals of thematic and content analysis are simply different from those of, for instance, a narrative analysis. The research objective was to describe how thematic contents are elaborated by groups of participants and to identify meanings that are valid across a wide range of participants, rather than to undertake an in-depth analysis of the inter-connections between meanings within one particular narrative.

Finally, acknowledging the inherent limitations of this study we hope that it can make a valuable contribution to the debate on research capacity building in ESD in Europe and other regions of the world, and, on the basis of the research findings, it would be possible to draw recommendations for further endeavours in the direction of improving inquiry on ESD research:

- It is beneficial to adopt an inductive approach (open questions), which is more time consuming in terms of data analysis, but ultimately enhances the authenticity of findings. The results need to be discussed between the study participants at different stages of the research process (respondent validation) during academic events (conferences, workshops, consultations), follow-up activities, through academic publications of participants, etc.

- It is essential to establish the research agenda, multi-voicedness and networking. Researchers with different levels of expertise and from different cultural and national backgrounds need to be equitably engaged in the process of collectively generating a global perspective.

- Political supporters should observe and encourage the directions of research that are in line with the global needs and developments and watch out for the warning signs of fragmentation, one-sidedness, injustice.

- The holistic nature of research should be preserved by integrating methodology and research topic and neither should be given preference at the expense of other. There is a need to balance all aspects of ESD research. 
- The interpretation of results will always depend on the perspective of the author of the research report, and it is therefore important to ask: Who is doing it? How is it done? Why is it done?

It is hoped that this study has raised a number of pertinent issues with regard to the ESD research agenda and presented possible ways of how these can be addressed. With the aim of incorporating a wider range of perspectives in the current debate we invite responses from the community of ESD researchers.

\section{References:}

Anadolu University. (2008). The $6^{\text {th }}$ International Conference Sustainable Development. Culture. Education: Collaboration on Education for Sustainable Development. Conference guide. June 4-7, 2008, Eskişehir, Turkey.

Ball, D. L., \& Forzani, F. M. (2007). 2007 Wallace foundation distinguished lecture: What makes education research "educational"? Educational Researcher, 36(9), 529-540. DOIi: 10.3102/0013189X07312896.

Baxter, L. A. (1991). Content analysis. In B. M. Montgomery \& S. Duck (Eds.), Studying interpersonal interaction (pp. 239-254). New York: The Guilford Press.

Bauer, M.W., \& Gaskell, G. D. (Eds.). (2000). Qualitative researching with text, image and sound: A practical handbook for social research (Developments in plant and soil sciences). Sage Publications Ltd.

Berliner, D. C. (2002). Comment: Educational research: The hardest science of all. Educational Researcher, 31(8), 18-20. DOI: 10.3102/0013189X031008018.

Bond, L. A., Holmes, T. R., Byrne, C. Babchuck, L., \& Kirton-Robbins, S. (2008). Movers and shakers: How and why women become and remain engaged in community leadership. Psychology of Women Quarterly, 32, 48-64.

Boyatzis, R. (1998). Transforming qualitative information: Thematic analysis and code development. Thousand Oaks, CA: Sage.

Bullough, Jr. R. V. (2006). Developing interdisciplinary researchers: What ever happened to the humanities in education? Educational Researcher, 35(8), 3-10. DOI: 10.3102/0013189X035008003.

Burkhardt, H. \& Schoenfeld, A. H. (2003). Improving educational research: Toward a more useful, more influential, and better-funded enterprise. Educational Researcher, 32(9), 3-14. DOI: 10.3102/0013189X032009003.

Cook, R., Cutting, R., \& Summers, D. (2010). If sustainability needs new values, whose values? Initial Teacher Training and the transition to sustainability. In P. Jones, D. Selby \& S. Sterling (Eds.), Sustainability education: Perspectives and practice across higher education, Chapter 17. London: Earthscan.

Creswell, J. W. (1998). Qualitative inquiry and research design: Choosing among traditions. Thousand Oaks, CA: Sage.

Daniels, S. E., \& Walker, G. B. (2001). Working through environmental conflict: The collaborative learning approach. Westport, CT: Praeger. 
DELLS. (2006). Education for sustainable development and global citizenship: A strategy for action, DELLS Information Document No: 017-06. Cardiff: Welsh Assembly Government.

Denby, L., Tilbury, D., \& Cerone, F. (2007). Sustainability in Noosa: A case study. Australian Research Institute in Education for Sustainability (ARIES) for the Australian Government Department of the Environment and Heritage. Sydney: ARIES.

DCELLS. (2008). Education for sustainable development and global citizenship: A common understanding for schools. Information Document No.065/2008. Cardiff: Welsh Assembly Government.

Dewey, J. (2009). Democracy and education: An introduction to the philosophy of education. New York: WLC Books.

Erickson, P. I., \& Kaplan, C. P. (2000). Maximizing qualitative responses about smoking in structured interviews. Qualitative Health Research, 10, 829-840.

Everett, J. (2008). Sustainability in higher education: Implications for the disciplines. Theory and Research in Education, 6(2), 237-251. DOI: 10.1177/1477878508091115.

Feuer, M. J., Towne, L., \& Shavelson, R. J. (2002). Scientific culture and educational research. Educational Researcher, 31(8), 4-14. DOI: 10.3102/0013189X031008004.

Härkönen, U. (2003). The new systems theory of early childhood education and preschool as a frame of reference for sustainable education. Journal of Teacher Education and Training, 2, 25-38.

Heimlich, J. E. (2007). Research trends in the United States: EE to ESD. Journal of Education for Sustainable Development, 1(2), 219-227. DOI: 10.1177/097340820700100212.

Henderson, K., \& Tilbury, D. (2004). Whole-school approaches to sustainability: An international review of whole-school sustainability programs. Report prepared by the Australian Research Institute in Education for Sustainability (ARIES) for the Australian Government Department of the Environment, Water, Heritage and the Arts.

Howe, K. R. (2008). Isolating science from the humanities: The third dogma of educational research. Qualitative Inquiry Online First, 1-19. Retrieved October 21, 2008, from http://qix.sagepub.com hosted at http://online.sagepub.com DOI: 10.1177/1077800408318302.

Hutchins, A. Hastie, A., Starkey, C., Hilton, S., \& Clark, R. (2005). An investigation into the benefits of prolonged study leave undertaken by general practitioners. Education for Primary Care, 16, 57-65.

Jithoo, V. (2010). To tell or not to tell; the childhood cancer conundrum: Parental communication and information-seeking. South African Journal of Psychology, 40(3), 351-360.

Joffe, H., \& Yardley, L. (2003). Content and thematic analysis. In D. F. Marks \& L. Yardley (Eds.), Research Methods for Clinical and Health Psychology (pp. 56-68). Sage Publications Ltd.

Keen, M., Brown, V. A., \& Dyball, R. (2005). Social learning: A new approach to environmental management. In M. Keen, V. A. Brown \& R. Dyball (Eds.), Social 
learning in environmental management: Towards a sustainable future (pp. 3-21). Earthscan, London.

Labaree, D. F. (2003). The peculiar problems of preparing educational researchers. Educational Research, 32(4), 13-22. DOI: 10.3102/0013189X032004013.

Lagemann, E. C. (1997). Contested terrain: A history of education research in the United States, 1890-1990. Educational Researcher, 26(9), 5-17. DOI: 10.3102/0013189X026009005.

Malterud, K. (1993). Shared understanding of the qualitative research process. Guidelines for the medical researcher. Family Practice, 10, 201-206.

Mandolini, C. (2007). Conditions, processes, and aims of teacher education: A philosophical perspective. Journal of Teacher Education for Sustainability, 7, 5-13.

McKeown, R. (2007). Setting the stage for a strategic research agenda for the UNDESD: A joint UNU-UNESCO workshop. Journal of Education for Sustainable Development, 1(1), 91-96. DOI: 10.1177/097340820700100115.

Miles, M., \& Huberman, M. (1994). Qualitative data analysis: An expanded sourcebook $\left(2^{\text {nd }}\right.$ ed.). Thousand Oaks, CA: Sage.

Minichiello, V., Aroni, R., Timewell, E., \& Alexander, L. (1990). In-depth interviewing: Researching people. Hong Kong: Longman Cheshire Pty Limited.

Moses, M. S. (2002). The heart of the matter: Philosophy and educational research. Review of Research in Education, 26(1), Chapter 1. DOI: 10.3102/0091732X026001001.

Patton, M. Q. (2002). Qualitative evaluation and research methods $\left(3^{\text {rd }}\right.$ ed.). Thousand Oaks, CA: Sage.

Paul, J. L., \& Marfo, K. (2001). Preparation of educational researchers in philosophical foundations of inquiry. Review of Educational Research, 71(4), 525-547. DOI: $10.3102 / 00346543071004525$.

Pothas, A. M., Andries, D., \& DeWet, J. (2001). Customer satisfaction: Keeping tabs on the issues that matter. Total Quality Management, 12, 83-94.

Salìte, I. (2008). Educational action research for sustainability: Constructing a vision for the future in teacher education. Journal of Teacher Education for Sustainability, 10, 5-16.

St.Pierre, E. A. (2006). Scientifically based research in Education: Epistemology and Ethics. Adult Education Quarterly, 56(4), 239-266. DOI: 10.1177/0741713606289 025.

Summers, D. (2010). Embedding education for sustainable development in initial teacher training in the lifelong learning sector. Teaching in Lifelong Learning, 2(1), 35-46.

Tashakkori, A., \& Teddlie, C. (1998). Mixed methodology: Combining qualitative and quantitative approaches. Thousand Oaks, CA: Sage.

Tilbury, D., \& Ross, K. (2005). Living change: Documenting good practice in education for sustainability in NSW. Macquarie University, Sydney and the Nature Conservation Council, NSW.

Weber, R. P. (Ed.). (1990). Basic content analysis (quantitative applications in the social sciences). Sage Publications, Inc.

Wright, T. (2007). Higher education for sustainability: Developing a comprehensive research agenda. Journal of Education for Sustainable Development, 1(1), 101-106. DOI: 10.1177/097340820700100114. 
Wright, T., \& Pullen, S. (2007). Examining the literature: A bibliometric study of ESD journal articles in the Education Resources Information Center Database. Journal of Education for Sustainable Development, 1(1), 77-90. DOI: 10.1177/09734082070010 0114

\section{Correspondence:}

Dr Anita Pipere, Institute of Sustainable Education, Faculty of Education and Management, Daugavpils University, Parādes Street 1-432, Daugavpils, LV-5401, Latvia. Tel.: + 371 654 27411. Email: anita.pipere@du.lv 